\title{
Magnetite Core-Shell Nanoparticles in Nondestructive Flaw Detection of Polymeric Materials
}

Mimi Hetti, $\dagger, \ddagger$ Qiang Wei, $\dagger, \ddagger$ Rainer Pohl, $\S$ Ralf Casperson, $\S$ Matthias Bartusch, $\perp$ Volker Neu, // Doris Pospiech †,* and Brigitte Voit $†, \ldots *$

† Leibniz Institut für Polymerforschung Dresden e.V., Hohe Straße 6, 01069 Dresden, Germany

† Organische Chemie der Polymere, Technische Universität Dresden, Germany

$\S$ Bundesanstalt für Materialforschung und -prüfung, 12205 Berlin, Germany,

$\perp$ Institute of Textile Machinery and High Performance Material Technology, Technische Universität Dresden, 01062 Dresden, Germany,

|| Institut für Metallische Werkstoffe, IFW Dresden, 01069 Dresden, Germany.

* Address correspondence to pospiech@ipfdd.de and voit@ipfdd.de. 


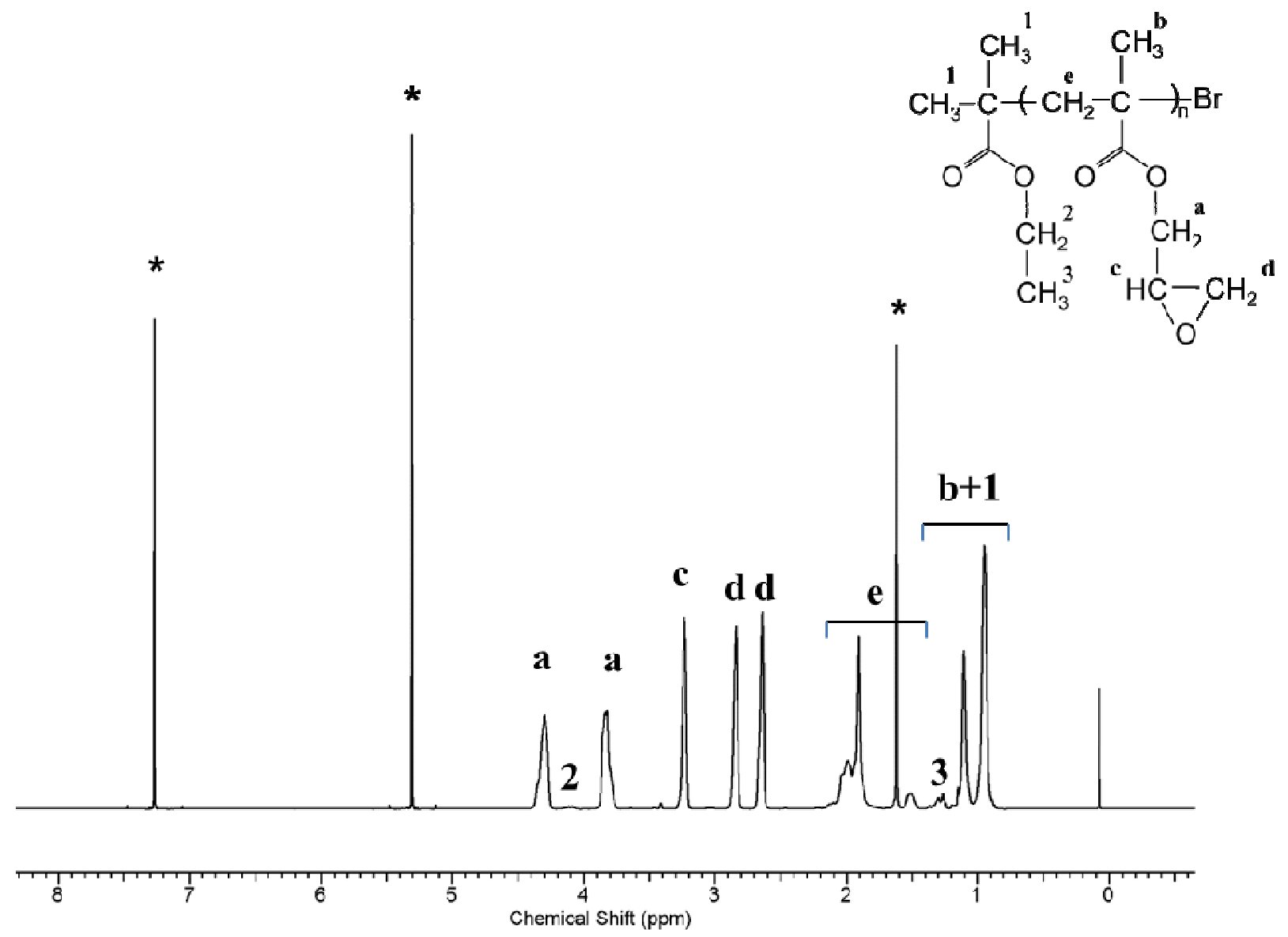

Figure S1: ${ }^{1} \mathrm{H}$ NMR spectrum of PGMA-Br measured in $\mathrm{CDCl}_{3}$. 


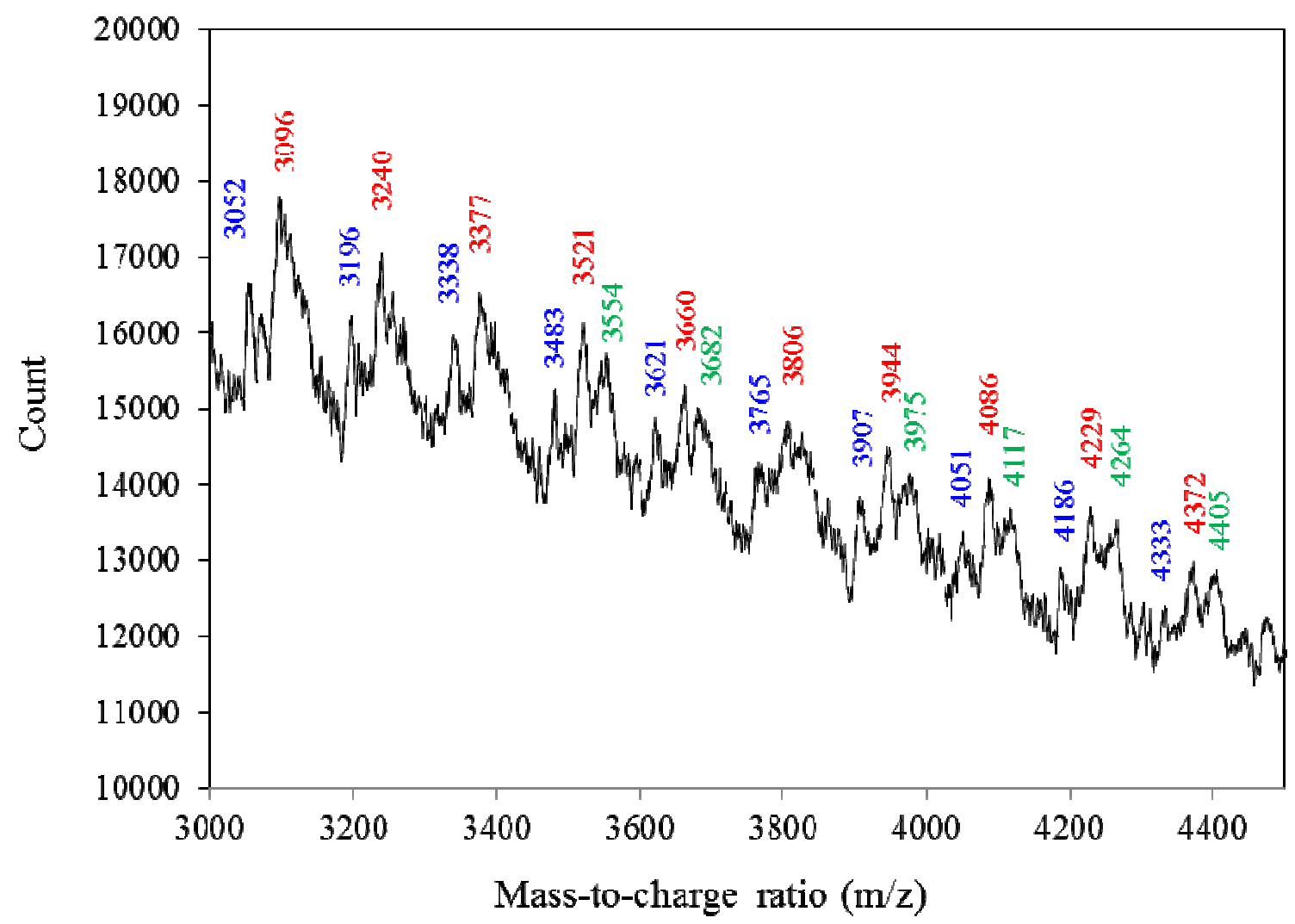

Figure S2: MALDI-TOF mass spectrum of PGMA. The three major series correspond to [115 $\left.\left(\mathrm{C}_{6} \mathrm{H}_{11} \mathrm{O}_{2}\right)+\mathrm{n}^{*} 142\left(\mathrm{C}_{7} \mathrm{H}_{10} \mathrm{O}_{3}\right)+79.9(\mathrm{Br})+23\left(\mathrm{Na}^{+}\right)\right]$(blue), initiator group with PGMA fragments $\left[115\left(\mathrm{C}_{6} \mathrm{H}_{11} \mathrm{O}_{2}\right)+\mathrm{n}^{*} 142\left(\mathrm{C}_{7} \mathrm{H}_{10} \mathrm{O}_{3}\right)+23\left(\mathrm{Na}^{+}\right)\right]$(green) and $\mathrm{Br}$ end group with PGMA fragments $\left[\mathrm{n}^{*} 142\left(\mathrm{C}_{7} \mathrm{H}_{10} \mathrm{O}_{3}\right)+79.9(\mathrm{Br})+23\left(\mathrm{Na}^{+}\right)\right](\mathrm{red})$. 


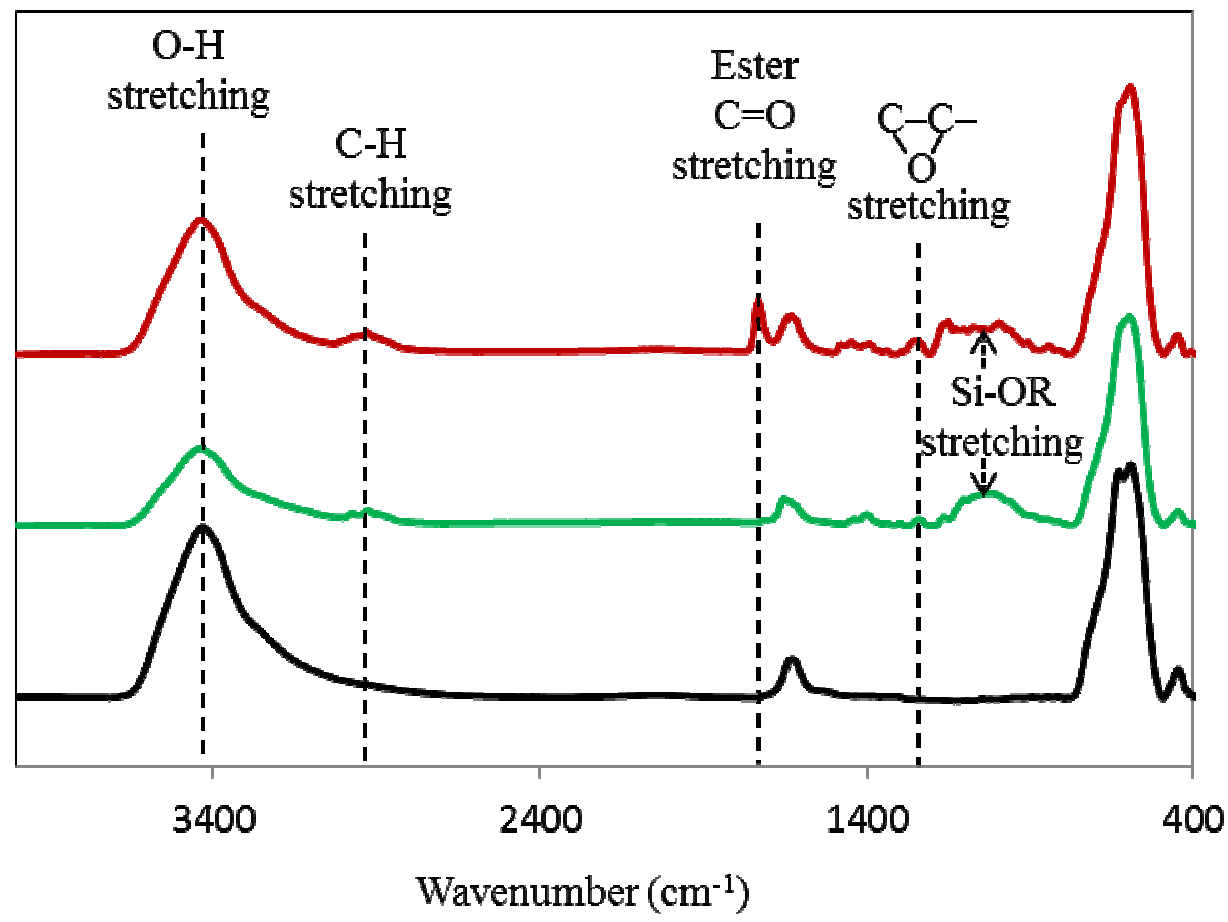

Figure S3: FTIR absorption spectra for the unmodified $\mathrm{Fe}_{3} \mathrm{O}_{4} \mathrm{NPs}$ (black), $\mathrm{Fe}_{3} \mathrm{O}_{4}$-MCTES NPs (green), and $\mathrm{Fe}_{3} \mathrm{O}_{4}$-PGMA NPs (red). 


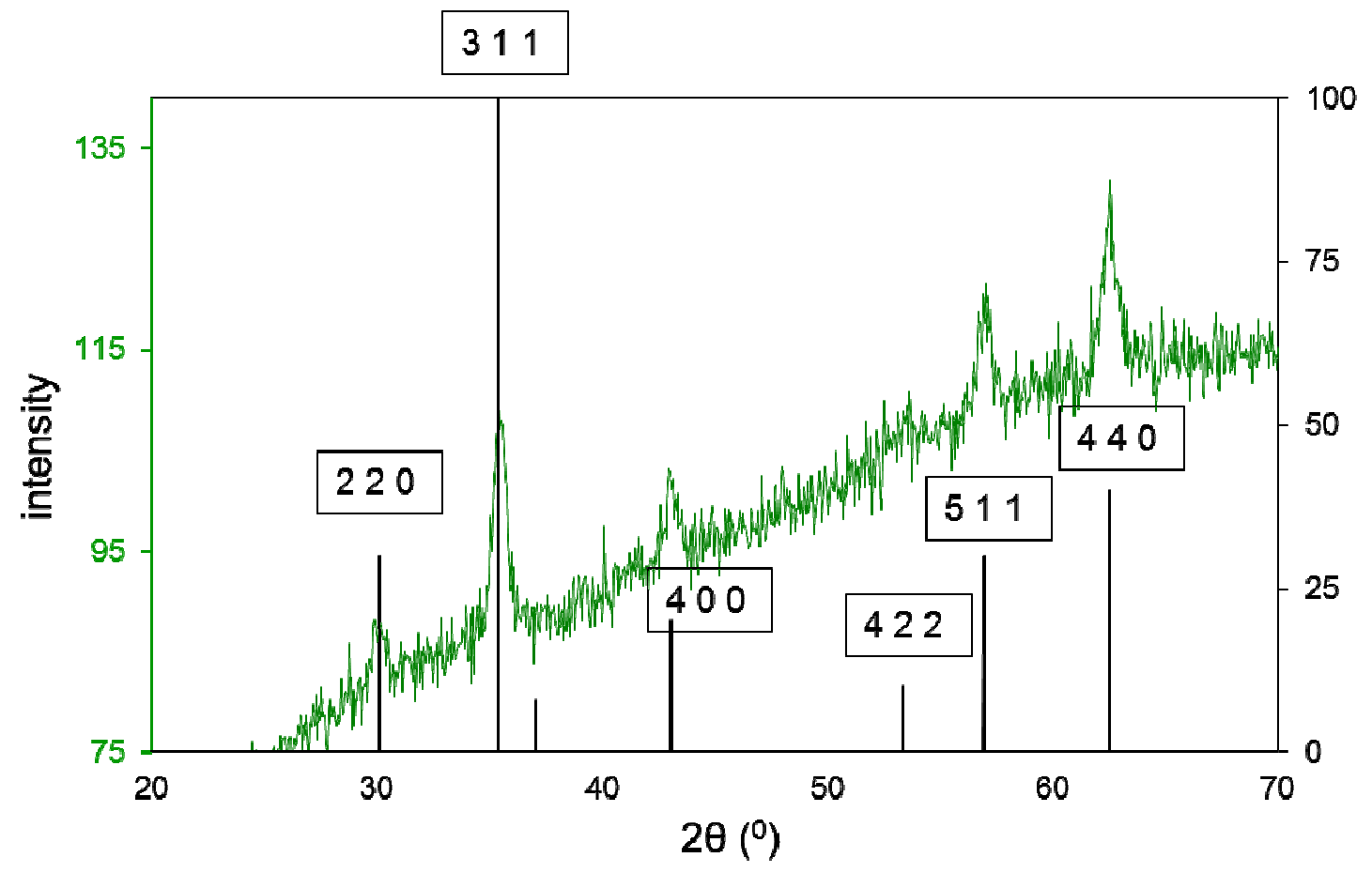

Figure S4: Comparison of XRD patterns of $\mathrm{Fe}_{3} \mathrm{O}_{4}$-PGMA NPs (green, left y-axis) with the database of magnetite cubic [file 19-629 of the database of JCPDS International Center for Diffraction Data] (black, right y-axis) with correspondence (hkl) (box). 


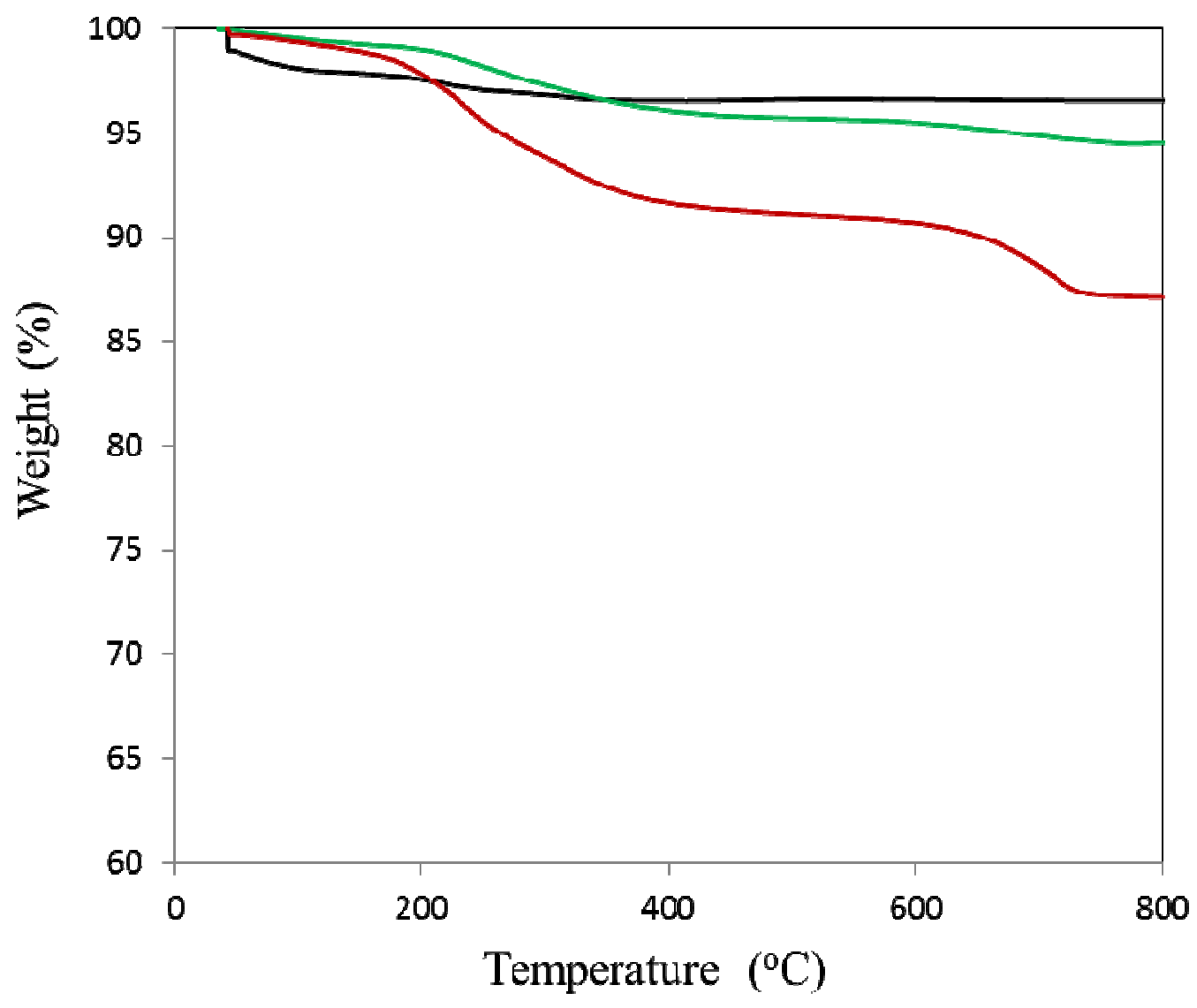

Figure S5: TGA thermograms of unmodified $\mathrm{Fe}_{3} \mathrm{O}_{4} \mathrm{NPs}$ (black), $\mathrm{Fe}_{3} \mathrm{O}_{4}$-MCTES NPs (green) and $\mathrm{Fe}_{3} \mathrm{O}_{4}$-PGMA NPs (red). 


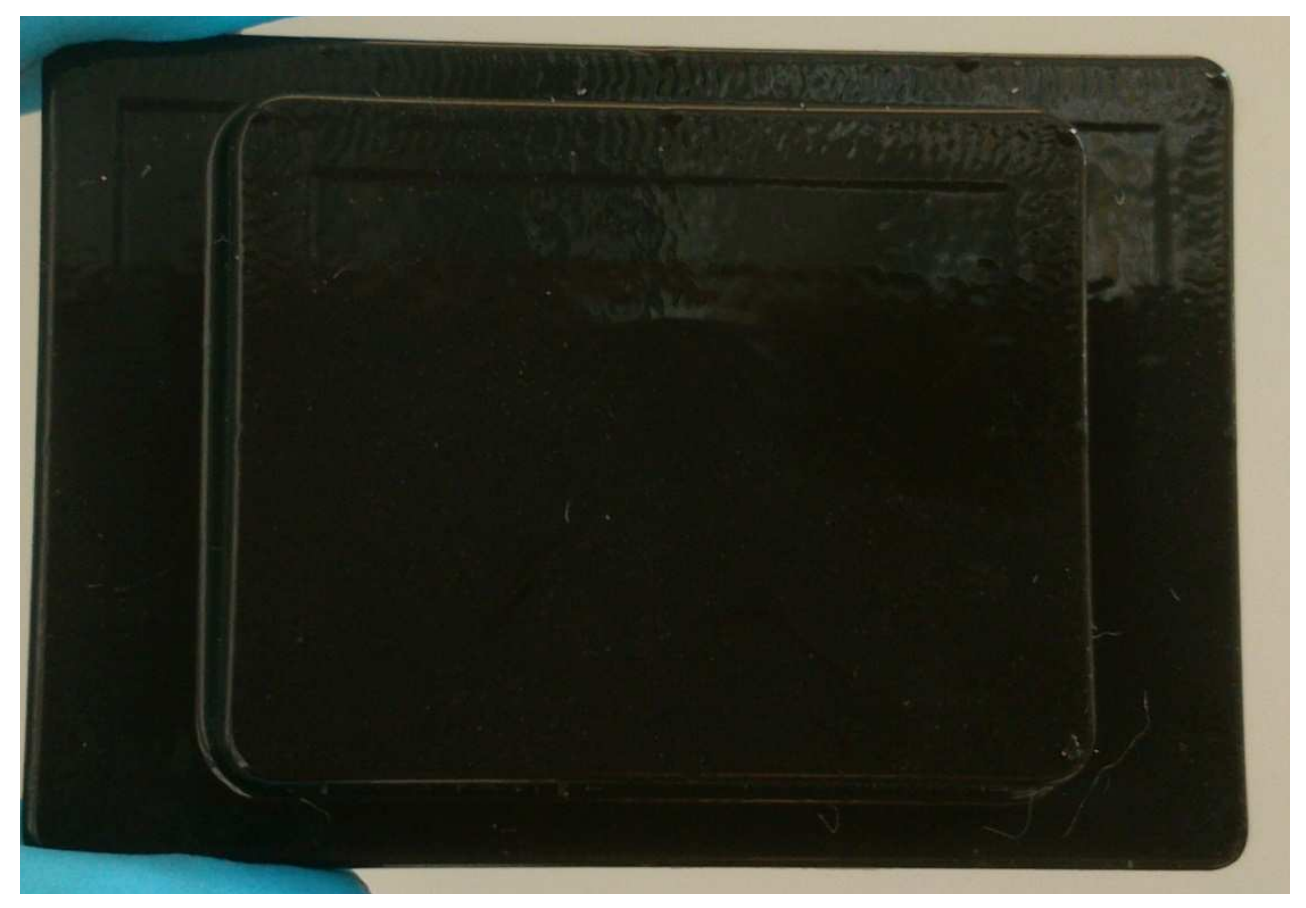

Figure S6: Magnetic epoxy nanocomposites (MENC) blended with $1.0 \%$ of $\mathrm{Fe}_{3} \mathrm{O}_{4}$-PGMA NPs. Appearance of the MENC sample. 


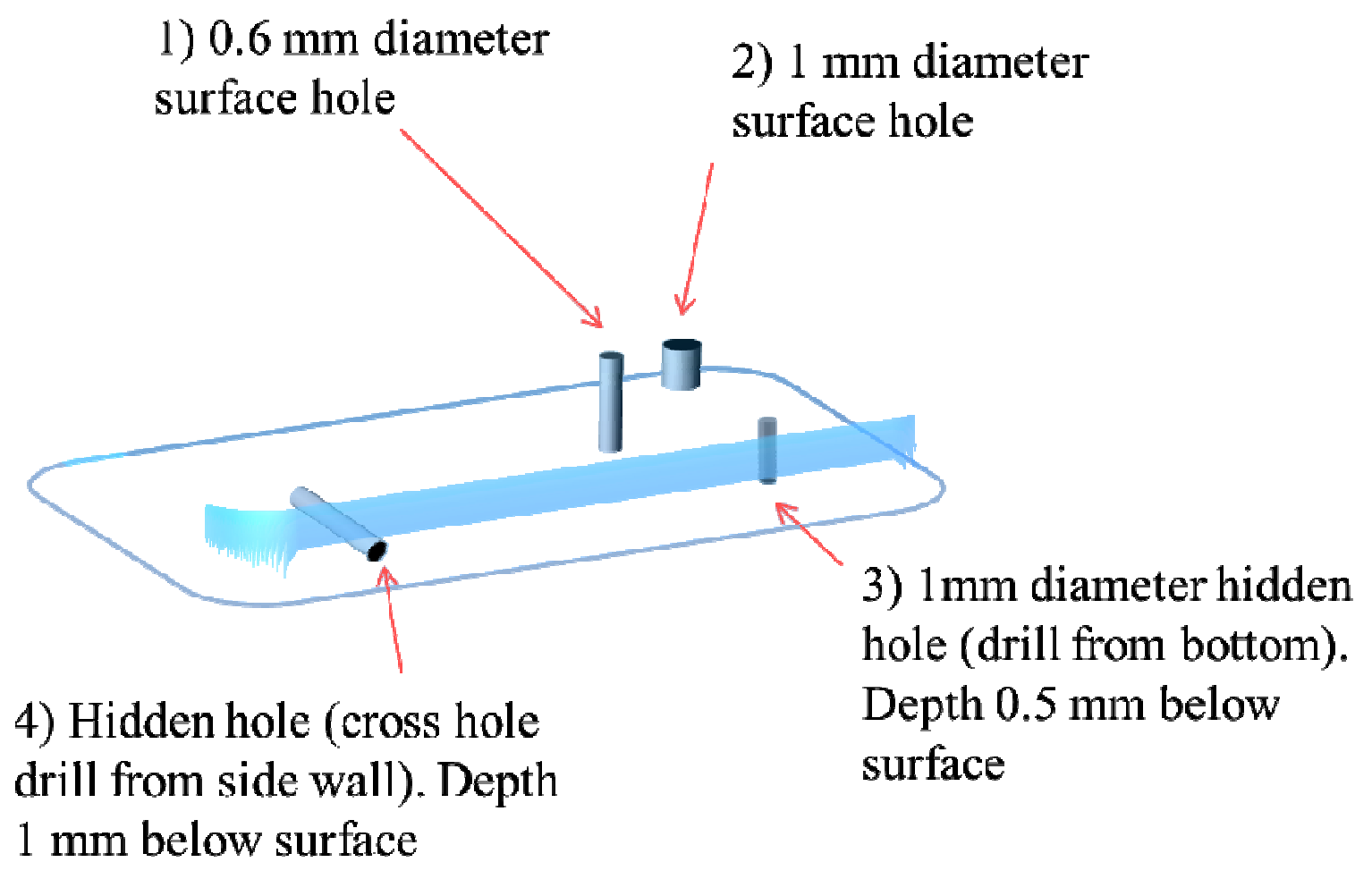

Figure S7: Sketch of defects made to the MENC in Figure S5. 